\title{
RAZGLEDI
}

\section{TEORETIČNO IN TERMINOLOŠKO O KONCEPTU PROŽNOSTI}

\author{
AVTORICA \\ dr. Lucija Lapuh \\ Fakulteta za informacijske študije, Inštitut za inovacije in tehnologije v regionalnem razvoju, Ljubljanska \\ cesta 31a, SI - 8000 Novo mesto, Slovenija \\ lucija.lapuh@fis.unm.si
}

DOI: $10.3986 / G V 89203$

UDK: 911.3:338.124.4:001.4

COBISS: 1.02

\section{IZVLEČEK}

\section{Teoretično in terminološko o konceptu prožnosti}

Geografi so se poleg ekonomistov z raziskavami hitro odzvali na spremembe, ki jih je prinesla recesija. Odziv na recesijo in okrevanje po njej preučujemo s konceptom prožnosti, ki je novost $v$ slovenski geografski literaturi. Namen članka je opredeliti koncept prožnosti ter pojasniti s tem konceptom povezane izraze, ki naj se pri preučevanju gospodarske krize in okrevanju po njej uporabljajo v slovenščini. Članek je razdeljen na obdobje pred recesijo, $v$ katerem regije izkazujejo gospodarsko rast, na obdobje recesije in na obdobje okrevanja po njej.

\section{KLJUČNE BESEDE}

ekonomska geografija, prožnost, ranljivost, odpornost, recesija, gospodarska kriza, terminologija

\section{ABSTRACT}

\section{Theoretically and terminologically about the concept of resilience}

Besides economists, geographers have quickly responded to changes made by the recession. A response to it and a recovery afterwards is investigated with the concept of resilience, which is a novelty in the Slovenian geographical literature. The purpose of this paper is to define the concept of resilience and to explain its terminology, which should be used to investigate economic crisis and recovery afterwards in the Slovenian language. This paper is divided, first, to the period before the recession, when regions conduct themselves with an economic growth, second to the period of recession, and third to the period of potential recovery afterwards.

\section{KEY WORDS}

economic geography, resilience, vulnerability, resistance, recession, economic crisis, terminology

Uredništvo je prispevek prejelo 20. marca 2017. 


\section{Uvod}

Poleg ekonomistov so se tudi geografi $\mathrm{z}$ raziskavami hitro odzvali na gospodarske spremembe, ki jih je prinesla recesija (Lapuh 2016b). Na recesijo po letu 2008 se v Sloveniji nanašajo predvsem geografski prispevki Lorberjeve (2010), Ravbarja (2011) in Kušarja (2012), doktorsko delo Lapuhove (2016a) ter diplomska dela Taboršakove (2011), Breznikove (2011), Strmškove (2014) in Martinčičeve (2014).

Odziv na recesijo in okrevanje po njej preučujemo s konceptom prožnosti, ki je v znanosti razumljen interdisciplinarno in je še vedno $v$ fazi razvoja. Iz začetne rabe v ekologiji, fiziki in psihiatriji se je razširil na področje naravnih nesreč in ekonomske geografije, ki je predmet obravnave tega prispevka. V novejši slovenski ekonomsko-geografski literaturi so koncept prožnosti preučevali predvsem Lapuhova (2016b), Komac in Lapuhova (2014) ter Komac s sodelavci (2013). Posledica razmeroma skromnega zanimanja slovenskih geografov za to področje je tudi slabše razvita terminologija - nekateri izrazi v slovenščini niso obstajali in jih je bilo treba posloveniti, za nekatere pa se je uporabljalo več izrazov in je bilo treba opredeliti najprimernejšega.

Namen članka je opredeliti in sistematično predstaviti koncept prožnosti ter pojasniti s tem konceptom povezane izraze (slika 1 ) iz ekonomske geografije, ki naj se v slovenščini na različnih prostorskih ravneh uporabljajo pri preučevanju gospodarske krize in okrevanju po njej. Metodološko je članek o konceptu prožnosti zasnovan na pregledu obstoječe, predvsem tuje literature in tudi prvih zametkov uporabe obravnavanih pojmov v slovenščini.

V prispevku je predstavljena prožnost na regionalni ravni, ki zajema tako statistične kot razvojne regije. Regija je ozemeljsko omejeno območje, ki s prepletanjem naravnogeografskih, družbenogeografskih in/ali zgodovinskih elementov tvori specifično funkcionalno zaokroženo celoto. Pomemben notranje raznolik sklop prvin prebivalstvenih in gospodarskih značilnosti regije je poimenovan družbeno-gospodarska sestava (angleško socio-economic structure) (Kladnik 2015).

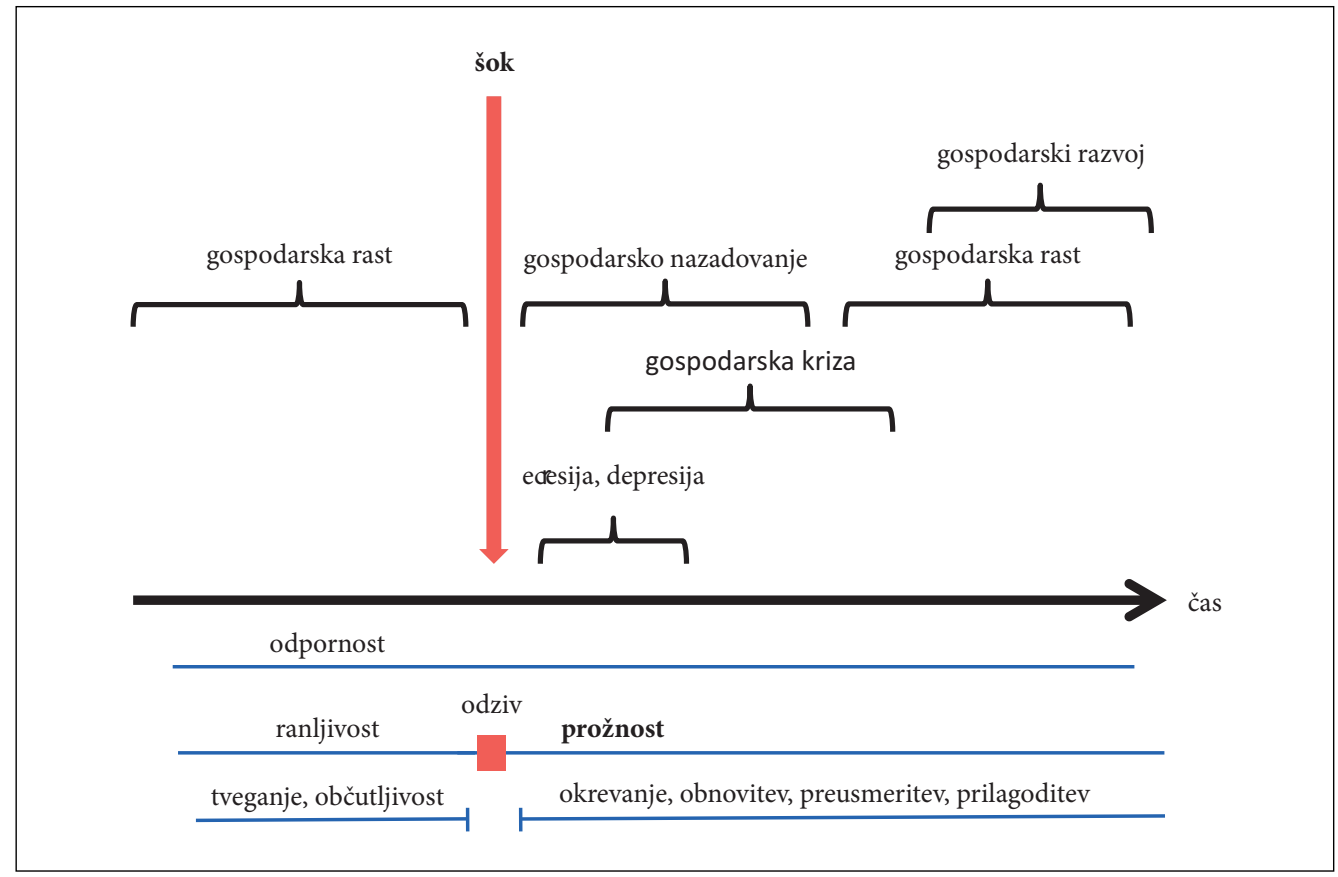

Slika 1: Izbrani pojmi, povezani s prožnostjo regij skozi čas. 


\section{Koncept prožnosti ob recesiji v okviru ekonomske geografije}

Gospodarski cikel je gibanje gospodarske dejavnosti med obdobjem rasti in obdobjem stagnacije. Cikel se zaključi po obdobju okrevanja. Gospodarski kazalniki, kot so bruto domači proizvod (BDP), stopnja registrirane brezposelnosti, obrestne mere, zadolženost in potrošniška poraba, nam pomagajo določiti, v kateri fazi cikla je gospodarstvo (medmrežje 3).

\section{1 Čas pred šokom}

Pred šokom so regije v obdobju gospodarske rasti (angleško economic growth), ki je opredeljena kot naraščanje sposobnosti gospodarstva za proizvodnjo blaga in opravljanje storitev (medmrežje 2), kar se kaže v večjih prihodkih regije ter posledično v višji kupni moči, številnejših investicijah (Nared 2006) in porastu blaginje.

\subsection{Vpliv šoka}

Ugoden razvoj v regiji in gospodarsko rast prekine nenaden pojav, poimenovan šok (angleško shock), ki vpliva na regijo. Če šok izvira iz bančništva, pride sprva do finančne krize (angleško financial crisis), ki nastane, ko je povpraševanja po denarju več, kot ga je na voljo v bankah. Ker se zmanjša likvidnost bank, so primorane prodati druge investicije oziroma celo propadejo (medmrežje 1). Posojilodajalci težje ocenijo nove vrste tveganj, zato posojilojemalci težje dobijo kredite, kar lahko privede do gospodarskega nazadovanja (angleško economic downturn), ki pomeni zmanjšanje gospodarske dejavnosti (Economic Crisis ... 2012) ter poslabšanje konkurenčnosti gospodarstva in lahko vodi v recesijo.

Recesija (angleško recession) pomeni pomembno zmanjševanje gospodarske dejavnosti, ki nastopi, ko je rast BDP v četrtletju v primerjavi s prejšnjim dvakrat zapored (šest mesecev) negativna (Uhlig 2010). Recesija sprva prizadene finančni sektor in nato vodi do korenitih sprememb v razvoju gospodarstva. Recesija privede do zmanjšanja proizvodnje in izvoza ter do prestrukturiranja gospodarstva (Lorber 2010). Učinki recesije so med drugim vidni v znižanju realnih prihodkov, odpuščanju delavcev (Lorber 2010), zvišani stopnji registrirane brezposelnosti in posledično zmanjšani trgovinski dejavnosti (Martin 2012). Recesija ima prehoden značaj in naj ne bi imela trajnega učinka na gospodarski razvoj, vendar pa močne in/ali pogoste recesije zavirajo dolgoročen razvoj gospodarstva (Martin 2012). Recesija se konča, ko prične BDP rasti in se hkrati znižuje stopnja brezposelnosti (Lapuh 2016a).

Recesija lahko vodi v gospodarsko depresijo (angleško depression), ki pomeni ekstremno in dolgotrajno recesijo (Martin 2012). Medtem, ko je recesija normalen del gospodarskega cikla, depresija to ni. Bistveni razliki med depresijo in recesijo sta v obsegu in dolžini trajanja. Za depresijo sta značilna upad BDP za več kot deset odstotkov ter recesija, ki traja vsaj tri leta. Značilnosti gospodarske depresije so neučinkovita gospodarska produktivnost, izjemno visoka stopnja registrirane brezposelnosti, številni bankroti, omejevalno posojanje denarja, bistveno manjša trgovska dejavnost, visoka nihanja med valutnimi tečaji ter deflacija (padanje cen). V času gospodarske depresije izjemno upadeta zaupanje potrošnikov in investiranje (medmrežje 3).

O gospodarski krizi (angleško economic crisis) govorimo, ko zaradi finančne krize pride do očitnega gospodarskega nazadovanja (medmrežje 1), vendar gospodarska kriza ni vezana na četrtletni padec BDP, temveč sega tudi na socialno področje ter na prostor kot celoto (Frankenberg, Thomas in Beegle 1999). Izraz se uporablja tudi za obdobje, v katerem že nastopi rahla gospodarska rast po krizi, vendar je gospodarstvo še zelo pod vplivom gospodarskega nazadovanja (na primer visoka brezposelnost, zmanjšanje izvoza) (Economic Crisis ... 2012). 


\subsection{Obdobje okrevanja po šoku}

Kako se regije ob izrednih dogodkih odzovejo in kakšen je njihov nadaljnji razvoj, poimenujemo prožnost (angleško resilience). V slovenščini smo v zadregi glede poimenovanja prožnosti. Raziskava Marotove (2014) je pokazala, da se slovenska strokovna javnost (akademska in raziskovalna sfera, za prostor pristojno ministrstvo in regionalne razvojne agencije) sooča s problemom prevoda - odpornost ali prožnost? Omenjena raziskava na podlagi izvedene delfi analize kaže, da je izraz prožnost najustreznejši prevod angleške sopomenke, kar se zdi ustrezno tudi glede na opredelitev po Slovarju slovenskega knjižnega jezika (medmrežje 4), ki prožnost opredeljuje širše od odpornosti. Tisti, ki so v omenjeni raziskavi menili, da gre za nov izraz, so izpostavili, da gre za celostno in dalj časa trajajoče okrevanje po izrednih dogodkih, medtem ko so ostali menili, da gre za pojem iz ekologije.

Prožnost je postala vodilen koncept za obravnavanje negotovosti in sprememb v različnih vedah ter na različnih področjih (Economic Crisis ... 2014). Izhaja iz naravoslovja, kjer so preučevali učinke šokov (naravnih in ekoloških nesreč, izjemnih posegov v prostor) na različne okoljske sisteme ter njihovo okrevanje. Pojem so najprej uporabljali v ekologiji, fiziki, psihiatriji (Manyena 2006) in psihologiji (Kaplan 1999), danes pa se uporablja predvsem pri naravnih nesrečah (na primer Komac s sodelavci 2013) in družbenih pojavih (na primer Kajzer 2008), zato se tako definicije prožnosti (Manyena 2006, 437) kot kazalniki, s katerimi jo merimo, razlikujejo. Nekatere definicije prožnosti izhajajo iz inženirske (a), druge iz ekološke (b) in tretje iz prilagoditvene teorije (c). Prvi dve teoriji sta z vidika preučevanja prožnosti regij deležni kritik.

a) Inženirska prožnost (angleško engineering resilience) je neoklasičen pristop, ki je opredeljen kot stabilnost sistema blizu ravnovesja (angleško equilibrium) (Holling 1973). Šok premakne gospodarstvo iz ravnovesja in samodejno sproži prilagoditev, ki povzroči vrnitev v ponovno ravnovesje, zato so gospodarstva samouravnotežena (Hill, Wial in Wolman 2008). Inženirska prožnost je sorodna ideji o elastičnosti - sposobnosti sistema, da lahko šok absorbira brez spremembe oblike. Teorija inženirske prožnosti domneva, da se regije, ki so na šok manj občutljive in torej odpornejše, hitreje vrnejo v ravnovesje. Regije, ki imajo v nekem obdobju po šoku enako ali večjo stopnjo razvoja kot pred njim, veljajo za prožne. Regije, ki tega po šoku ne dosežejo, so neprožne (Hill, Wial in Wolman 2008). Tak pristop vrnitve v ravnovesje, kakršno je bilo pred šokom, je za preučevanje prožnosti regij manj primeren, saj v resničnosti prihaja do sprememb, tudi ko ne pride do šoka.

b) Ekološka prožnost (angleško ecological resilience) zagovarja moč motnje, ki jo regija lahko absorbira, preden se poruši ravnovesje oziroma preden se regija premakne v novo ravnovesje (Martin 2012). Ta teorija prožnosti zagovarja, da ima gospodarstvo lahko več ravnovesij, pri čemer je novo ravnovesje odvisno od prejšnjega. Pri ekološki prožnosti je pomembna jakost šoka, ki ga regija lahko absorbira, preden prilagodi sestavo (Christopherson, Michie in Tyler 2010; Pike, Dawley in Tomaney 2010). Prožna regija je tista, ki se učinkovito prilagodi in dolgoročno izboljša gospodarsko rast (Simmie in Martin 2010). Kriza lahko spodbudi preoblikovanje sektorske sestave regij (Pike, Dawley in Tomaney 2010), kar pojasnjuje schumpeterjanski pristop (angleško Schumpeterian notion of gales of creative destruction), ki razlaga ukinitev nekaterih zastarelih ali neproduktivnih dejavnosti in ustvarjanje priložnosti za razvoj novih (Simmie in Martin 2010).

Teorija ravnovesja oziroma več ravnovesij je v praksi malo verjetna ter je bolj primerna za modeliranje (Christopherson, Michie in Tyler 2010), saj v nasprotju s fizičnimi in ekološkimi sistemi gospodarstvo nikoli ni v ravnovesju (Martin 2012). Teorija ravnovesja oziroma več ravnovesij se osredotoča na državno raven in težko pojasnjuje prožnost regij. Ekonomski geografi se distancirajo od tega koncepta, ki so ga razvili ekonomisti. Bolj so naklonjeni odprtim evolucijskim pristopom, ki usmerjajo svojo pozornost na zmožnost dolgoročne prilagoditve regij (Mackinnon in Derickson 2012). 
c) Prilagoditvena prožnost (angleško adaptive resilience) ne vključuje zgolj sposobnosti regij, da se uprejo šoku, temveč tudi prestrukturiranje, prilagoditev in obnovitev gospodarske sestave ter dolgoročno ohranitev sprejemljive poti gospodarske rasti in zaposlovanja (Martin 2012). Kaj pomeni sprejemljiva pot rasti, v znanstveni literaturi ni dorečeno (Economic Crisis ... 2014). Ta teorija dojema prožnost kot stalno spreminjajoč, dinamičen proces (Simmie in Martin 2010). Prožnost regij se spreminja ne le zaradi razlik v vzrokih in naravi posameznih šokov, ampak zato, ker se lahko dejavniki, ki oblikujejo prožnost, sami razvijajo in spreminjajo (Martin 2012). Prožne regije so dolgoročno gospodarsko uspešne in se prilagajajo spremembam (Christopherson, Michie in Tyler 2010). V neprožnih regijah se gospodarstvo ne uspe uspešno preoblikovati in ostane zaprto (angleško locked in) v zastareli strukturi ter posledično nazaduje.

Koncept prilagoditve je za razlago prožnosti regij bolj uporaben kot koncepta ravnovesja in več ravnovesij (Christopherson, Michie in Tyler 2010), saj prožnosti ne moremo opredeliti s hitrostjo okrevanja ali s sposobnostjo vrnitve na vrednosti pred šokom (Martin 2012).

Koncept prožnosti je postal priljubljen zaradi večje občutljivosti na zaznavanje tveganja ter prepričanja, da globalizacija vpliva na večjo prepustnost vplivov, ki so nekoč veljali za zunanje (Christopherson, Michie in Tyler 2010). Izraz prožnost se pri dosedanji uporabi v regionalnih in urbanih študijah navezuje na sposobnost lokalne družbeno-gospodarske sestave, da se po recesiji obnovi in deluje »elastično« (Martin 2012). V uporabi je tudi izraz gospodarska prožnost, ki pa ne zajema družbenega vidika prožnosti regij - na primer znižanja stopnje registrirane brezposelnosti. Izraz prožnost je večkrat uporabljen tudi pomensko nepravilno, podobno kot izraza dinamičen $\mathrm{v}$ petdesetih ali trajnosten $\mathrm{v}$ devetdesetih letih prejšnjega stoletja (Rose 2009). Prožnost ne izraža uspešnosti regij pred recesijo kot tudi ne jakosti šoka, po katerem so skušale okrevati (Lapuh 2016a).

Prožnost je v tem članku definirana kot sposobnost regij, da se v čim krajšem času zoperstavijo negativnemu zunanjemu vplivu, ga absorbirajo in premagajo, kar predstavlja odgovor na povzročeno spremembo z iskanjem prilagoditve, pri čemer je pomemben zgodovinski razvoj regije. Prožnost se meri s kazalnikoma, ki vključujeta tako gospodarsko kot družbeno področje: BDP na prebivalca in stopnja registrirane brezposelnosti (Lapuh 2016a). Regije s prožnim gospodarstvom in neprožnim trgom dela ne moremo obravnavati kot prožne. Poleg okrevanja gospodarstva morajo biti prioritete razvoja regij tudi dolgoročno ohranjanje zaposlenosti, dvig življenjskega standarda in družbeno blagostanje prebivalcev.

Na podlagi analize slovenskih regij in občin (Lapuh 2016a) je bilo ugotovljeno, da so prožne občine podjetništvu namenjale večjo pozornost, da so bile manj specializirane, bolj izvozno usmerjene, gosteje poseljene, imele so ugodnejšo demografsko sestavo in bile dostopnejše.

\subsection{Drugi izrazi, povezani s prožnostjo}

Pred recesijo je za regije značilna gospodarska rast, hkrati so zaradi lastnih družbeno-gospodarskih značilnosti različno dovzetne za morebitne nenadne negativne vplive, kot je recesija. Ranljivost (angleško vulnerability) pojasnjujejo (Christmann in Ibert 2012) kot občutljivost in jo pripisujejo notranjim posebnostim gospodarstev (na primer izvozni usmerjenosti in sektorski sestavi), ki vplivajo na izpostavljenost regij zunanjim šokom (Briguglio s sodelavci 2008). Poznavanje procesov in pojavov, ki pripomorejo k manjši ranljivosti, je pomembno pri prizadevanju za uspešnejši dolgoročni razvoj regij. Ranljive regije ne smejo biti vdane v usodo, ampak lahko sprejmejo ukrepe, da se ranljivosti zoperstavijo in tako $\mathrm{z}$ njenim obvladovanjem gradijo prožnost. Prožnost raziskujemo z namenom zmanjšanja ranljivosti in izboljšanja odziva družbe na negativne gospodarske vplive. Od devetdesetih let prejšnjega stoletja je prožnost pridobivala pomen in začela konkurirati konceptu ranljivosti predvsem zaradi svojega pozitivnega pomena, ki je pri ranljivosti izrazito negativen - ranljivost se pojmuje kot občutljivost, prožnost pa kot sposobnost prilagoditve (Christmann in Ibert 2012). Odnos med pojmoma ni dorečen, saj se ju razume kot pomensko nasprotna ali pa kot prepletajoča se procesa. 
Ranljivost je soodvisna s tveganjem (angleško risk), ki pomeni izpostavljenost nevarnosti, in s pripravljenostjo skupnosti, da tveganje zmanjša (Manyena 2006). Kolikšno stopnjo tveganja ima določena regija, je odvisno od nevarnosti, ki ji preti, od ranljivosti regije, nastalih posledic in njene prožnosti (Rose 2009). Tveganje je negativno povezano $\mathrm{z}$ ranljivostjo in pozitivno s prožnostjo (Graziano 2013). Povečujejo ga pomanjkljiva informiranost, pripravljenost in organizacija, pomanjkljivo obveščanje in politična nestabilnost ter nestabilnost gospodarstva (Manyena 2006).

$\mathrm{V}$ obdobju gospodarske rasti so regije različno odporne na nenadne negativne vplive, kot je recesija. Odpornost (angleško resistance) je sposobnost regij, da se uprejo šoku (Economic Crisis ... 2012), tako da ne pride do zmanjšanja gospodarske dejavnosti in povišanja stopnje registrirane brezposelnosti. Regije, katerih gospodarska rast se ob šoku ne spremeni, so odporne na šok (Hill, Wial in Wolman 2008). Odpornost je odvisna od ranljivosti in občutljivosti regij ter od odziva gospodarstva na recesijo (Martin 2012).

Regije so stalno podvržene spremembam, vendar na nekatere šok ne vpliva, medtem ko druge še leta po njem ne uspejo okrevati (angleško recovery). Okrevanje je sposobnost regij, da so po šoku ponovno uspešne - med drugim izkazujejo gospodarsko rast in nizko stopnjo registrirane brezposelnosti. Obnovitev (angleško renewal) je ponovna vzpostavitev gospodarske rasti (na primer proizvodnje, zaposlitve in dohodkov) na raven pred šokom (Martin 2012). Preusmeritev (angleško re-orientation) pove, v kolikšni meri regije po šoku prilagodijo svojo gospodarsko sestavo (Economic crisis ... 2012). Prilagoditev (angleško adaptation) je opredeljena kot prizadevanje k vnaprej (pred krizo) začrtani poti, ki jo zaznamuje močno sodelovanje med družbenimi akterji določenega območja (Pike, Dawley in Tomaney 2010).

Preglednica 1: Priporočeni slovenski izrazi koncepta prožnosti.

\begin{tabular}{lll}
\hline & slovenski izraz & angleški izraz \\
\hline čas pred šokom & gospodarska rast & economic growth \\
\hline vpliv šoka & šok & shock \\
\cline { 2 - 3 } & finančna kriza & financial crisis \\
\cline { 2 - 3 } & gospodarsko nazadovanje & economic downturn \\
\cline { 2 - 3 } & recesija & recession \\
\cline { 2 - 3 } obdobje okrevanja po šoku & gospodarska kriza & depression \\
\hline drugi izrazi povezani s prožnostjo & prožnost & economic crisis \\
\cline { 2 - 3 } & ranliivost & resilience \\
\cline { 2 - 3 } & tveganje & vulnerability \\
\cline { 2 - 3 } & odpornost & risk \\
\hline okrevanje & resistance \\
\cline { 2 - 3 } & obnovitev & recovery \\
\cline { 2 - 3 } & preusmeritev & renewal \\
\cline { 2 - 3 } & prilagoditev & re-orientation \\
\cline { 2 - 3 } & gospodarski razvoj & adaptation \\
\hline
\end{tabular}


V nasprotju z gospodarsko rastjo, ki je fenomen tržne produktivnosti in dviga BDP, je gospodarski razvoj (angleško economic development) proces, katerega cilj je gospodarsko in družbeno blagostanje prebivalcev in h kateremu naj regije stremijo v svojem razvoju po šoku. Gospodarski razvoj se nanaša na rezultate usklajenega delovanja razvojnih akterjev pri zagotavljanju kakovosti življenja ter doseganju življenjskega standarda oziroma blagostanja določenega območja. Razumemo ga lahko tudi kot kakovostne in količinske spremembe $\mathrm{v}$ gospodarstvu ter družbi, in sicer kot rast človeškega kapitala ter izboljšanje infrastrukture, regionalne konkurenčnosti, okoljske trajnosti, socialne vključenosti, zdravja in varnosti (Leser s sodelavci 1997).

\section{Sklep}

V prispevku je opredeljen koncept prožnosti. Pojasnjeni so s tem konceptom povezani izrazi (preglednica 1), ki naj se jih uporablja v slovenščini pri preučevanju gospodarske krize in okrevanja po njej na področju ekonomske geografije ter širše na različnih prostorskih ravneh. Koncept prožnosti ima različne teorije in definicije: od vrnitve v ravnovesje (inženirska prožnost) in več ravnovesij (ekološka prožnost), do prilagoditvene sposobnosti (prilagoditvena prožnost). Prožnost regij naj se interpretira kot sposobnost regij, da se uprejo šoku oziroma ga absorbirajo ter, da v relativno kratkem obdobju po njem okrevajo. Merimo jo s spremembo BDP na prebivalca in stopnjo registrirane brezposelnosti. Na prožnost regij poleg jakosti šoka vpliva tudi njihova družbeno-gospodarska sestava.

\section{Viri in literatura}

Breznik, R. 2011: Gospodarske spremembe v Sloveniji in državah Zahodnega Balkana. Diplomsko delo, Filozofska fakulteta Univerze v Mariboru. Maribor.

Briguglio, L., Cordina, G., Farrugia, N., Vella, S. 2008: Economic Vulnerability and Resilience. UNU-WIDER Research Paper No. 55. Helsinki.

Christmann, G. B., Ibert, O. 2012: Vulnerability and resilience in a socio-spatial perspective. Raumforschung und Raumordnung 70-4. DOI: https://doi.org/10.1007/s13147-012-0171-1

Christopherson, S., Michie, J., Tyler, P. 2010: Regional resilience: theoretical and empirical perspectives. Cambridge Journal of Regions, Economy and Society 3-1. DOI: https:/doi.org/10.1093/cjres/rsq004

Economic Crisis: Resilience of Regions, 2012. Medmrežje: http://www.espon.eu/export/sites/default/ Documents/Projects/AppliedResearch/ECR2/ECR2_inception_report.pdf (23.2.2017).

Economic Crisis: Resilience of Regions, 2014. Medmrežje: https:/www.espon.eu/main/Menu_Projects/ Menu_ESPON2013Projects/Menu_AppliedResearch/ECR2.html (23.2.2017).

Frankenberg, E., Thomas, D., Beegle, K. 1999: The real costs of indonesia's economic crisis: Preliminary findings from the Indonesia family life surveys. Labour and Population Program Working Paper Series 99-4.

Graziano, P. 2013: Vulnerability and resilience of the economic, social and environmental dimensions of Italian provinces. Regional Studies Association European Conferece 2013. Medmrežje: http://www.regionalstudies.org/uploads/Graziano2013.pdf (23.2.2017).

Hill, E. W., Wial, H., Wolman, H. 2008: Exploring Regional Economic Resilience. Berkeley Institute of Urban and Regional Development. Medmrežje: http://escholarship.org/uc/item/7fq4n2cv\#page-1 (23.2.2017).

Holling, C. S. 1973: Resilience and stability of ecological systems. Annual Review of Ecology and Systematics 4. DOI: https://doi.org/10.1146/annurev.es.04.110173.000245

Kajzer, A. 2008: Varna prožnost v Sloveniji - kje smo in kako naprej? IB revija 42, 3-4.

Kaplan, H. B. 1999: Toward an understanding of resilience: a critical review of definitions and models. Resilience and Development: Positive Life Adaptations. New York. 
Kladnik, D. 2015: Družbenogospodarska sestava. Kras. Medmrežje: http://www.razvojkrasa.si/si/ ljudje/128/article.html (24.7.2015).

Komac, B., Lapuh, L. 2014: Nekaj misli o konceptu prožnosti v geografiji naravnih nesreč. Geografski vestnik 86-1. DOI: https://doi.org/10.3986/GV86103

Komac, B., Lapuh, L., Nared, J., Zorn, M. 2013: Prožnost prostorskih sistemov v primeru kriznih dogodkov. Nove razvojne perspektive, Regionalni razvoj 4. Ljubljana.

Kušar, S. 2012: Izbrani prostorski učinki globalne finančne in gospodarske krize v Ljubljani. Urbani izziv 32-2. DOI: https://doi.org/10.5379/urbani-izziv-2012-23-02-004

Lapuh, L. 2016a: Ekonomskogeografsko vrednotenje prožnosti regij v času recesije. Doktorsko delo, Filozofska fakulteta Univerze v Ljubljani. Ljubljana.

Lapuh, L. 2016b: Measuring the impact of the recession on Slovenian statistical regions and their ability to recover. Acta geographica Slovenica 56-2. DOI: https://doi.org/10.3986/AGS.764

Leser, H., Haas H., Mosimann, T., Reinhard, P. 1997: Diercke Wörterbuch Allgemenine Geographie. München.

Lorber, L. 2010: Global crisis - an opportunity for completion of structural transformation of Slovenian economy. Folia geographica 40-15.

Mackinnon, D., Derickson, D. 2012: Beyond regional resilience: social relations, scale and adaptation. American Association of Geographers Annual Meeting. Medmrežje: http://meridian.aag.org/ callforpapers/program/AbstractDetail.cfm?AbstractID=44118 (23.2.2017).

Manyena, S. B. 2006: The concept of resilience revisited. Disasters 30-4. DOI: https://doi.org/10.1111/ j.0361-3666.2006.00331.x

Martinčič, L. 2014: Finančna in gospodarska kriza v ZDA po letu 2007. Zaključno seminarsko delo, Filozofska fakulteta Univerze v Ljubljani. Ljubljana.

Marot, N. 2014: Kratka raziskava o izrazu prožnost mest. Sklepno poročilo, Biotehniška fakulteta Univerze v Ljubljani. Ljubljana.

Martin, R. 2012: Regional economic resilience, hysteresis and recessionary shocks. Journal of Economic Geography 12-1. DOI: https://doi.org/10.1093/jeg/lbr019

Medmrežje 1: http://www.businessdictionary.com/ (23.2.2017).

Medmrežje 2: www-personal.umich.edu/ alandear/glossary/e.html (17.2.2017).

Medmrežje 3: http://www.financnislovar.com/definicije/ekonomska-depresija.html (23.2.2017).

Medmrežje 4: http://bos.zrc-sazu.si/sskj.html (23.2.2017).

Nared, J. 2006: Vplivi regionalne politike na razvoj prostorskih struktur v Sloveniji: teorije, modeli in aplikacija. Doktorsko delo, Filozofska fakulteta Univerze v Ljubljani. Ljubljana.

Pike, A., Dawley, S., Tomaney, J. 2010: Resilience, adaptation and adaptability. Cambridge Journal of Regions, Economy and Society 3-1. DOI: https://doi.org/10.1093/cjres/rsq001

Ravbar, M. 2011: Izgubljamo enostavna delovna mesta, več pa je zahtevnih zaposlitev: gospodarska kriza in trg delovne sile 2008-2010. Delo (12.9.2011) 53-211.

Rose, A. 2009: Economic resilience to disasters. CARRI Research Report 8. Medmrežje: http://www.resilientus.org/wp-content/uploads/2013/03/Research_Report_8_Rose_1258138606.pdf(27.5.2015).

Simmie, J., Martin, R. 2010: The economic resilience of regions: towards an evolutionary approach. Cambridge Journal of Regions, Economy and Society 3-1. DOI: https://doi.org/10.1093/cjres/rsp029

Strmšek, V. 2014: Vpliv finančno-gospodarske krize na gospodarsko strukturo Šaleške doline. Zaključno seminarsko delo, Filozofska fakulteta Univerze v Ljubljani. Ljubljana.

Taboršak, J. 2011: Nastajanje inovativne regije na razvojni osi Maribor-Celje. Diplomsko delo, Filozofska fakulteta Univerze v Mariboru. Maribor.

Uhlig, H. 2010: Euro Area Business Cycle Dating Committee: Determination of the 2009 Q2 trough in economic activity. Medmrežje: http://www.voxeu.org/article/when-did-eurozone-recessionend (23.2.2017). 


\section{Summary: Theoretically and terminologically about the concept of resilience}

(translated by the author)

A response to a recession and a recovery afterwards is examined by the concept of resilience, which is used interdisciplinarily and is still an evolving concept. In this article resilience is examined within the economic geography. A consequence of Slovenian geographers' relatively modest interest of resilience is less developed terminology.

The purpose of this article is to determine and to systematically present the concept of resilience and to explain with this concept related terminology, which should be used in examining an economic crisis and a recovery afterwards in the Slovenian language on different spatial levels.

Before the recession regions are in a period of an economic growth, which is determined as "an increase over time in the capacity of an economy to produce goods and services and (ideally) to improve the well-being of its citizens « (medmrežje 2). Unlike an economic growth, which is a phenomena of a market productivity and the rise of gross domestic product (GDP), the economic development is a process, which goal is economic and social welfare of inhabitants.

A sudden shock influences regions and interrupts their prosperous development. A shock causes an economic downturn which is a reduction of economic activities (Economic Crisis ... 2012) and slowness of economic growth (Leser et al. 1997).

The recession means an important $»$ decline in the level of an economic activity, usually visible in two or more consecutive quarters of negative growth in GDP « (Uhlig 2010). The depression, which is an extreme and a long-term recession, can follow the recession (Martin 2012). The economic downturn, which is a negative change in the economy (medmrežje 1), is not tied to quarterly fall of GDP, but also includes a social sphere and a place as whole (Frankenberg, Thomas and Beegle 1999). The term is also used during a slight economic growth after the crisis, when the economy is still under the economic regression (etc. a high unemployment rate, a reduction of export ...) (Economic Crisis ... 2012).

How regions react to an extraordinary event and what their further development will be like is described by the concept of resilience. The most proper term in Slovenian language, based on the results of the Delphi-analysis, is "prožnost « (Marot 2014). Resilience has become the leading concept for treating uncertainties and changes. There is not a unique definition of resilience. Some definitions of the resilience arise from engineering, other from ecological and third from the adaptation theory. The engineering resilience is a neoclassical approach which emphasises bouncing back to the equilibrium. The ecological resilience emphasises the strength of a disturbance that a region can absorb before it falls to the equilibrium or moves to a new one (Martin 2012). With the evolutionary resilience the extent of a disturbance that a region can absorb before it changes its structure is important (Christopherson, Michie and Tyler 2010; Pike, Dawley and Tomaney 2010). The adaptive resilience does not include only a resistance or the ability of a region to withstand the shock, but also a recovery to restructure, to adapt and to recover the economic structure and to preserve the acceptable growth rate and employment in time (Martin 2012). The first two mentioned theories have received a lot of criticism. The concept of an adaptation is more useful for resilience explanation than concepts of equilibrium and more equilibriums (Christopherson, Michie and Tyler 2010), because with the concepts of equilibrium the time is divided to the period before the shock and after it (Martin 2012). The resilience has been defined as the ability of a regional economy to withstand, absorb, or overcome an external economic shock and to recover from it relatively quickly. The concept of resilience has become popular due to a greater sensitivity to a perceived risk and a belief of globalisation's greater permeability of influences, which were once perceived as external (Christopherson, Michie and Tyler 2010).

The vulnerability is defined as sensitivity (Christmann and Ibert 2012). It depends on inner economy's specialities, which influence the regions' exposition to the external disturbances (Briguglio et al. 2008), as is the recession. While vulnerability is perceived as sensitivity, resilience is understood as an ability of a system to adapt (Christmann and Ibert 2012). The relation between both terms is not 
determined: vulnerability as a contrast to resilience, resilience and vulnerability as individual and intertwined processes. Resilience after the negative economic influence, as is the recession, can be examined with the purpose to reduce vulnerability and to improve society's response to those changes.

The risk is a function of threat, vulnerability, consequences and resilience (Rose 2009). Graziano (2013) considered it negatively connected with the vulnerability and positively with resilience.

During the period of an economic growth and development regions are differently resistant to sudden negative influences as is the recession. The resistance is an ability of the area to withstand the shock (Economic Crisis ... 2012), so that an economic activity does not reduce and the unemployment not rise. Regions which economic growth has not been changed due to the shock are resistant (Hill, Wial and Wolman 2008). Economic growth's renewal or resumption, re-establishment, redirection and adaptation (etc. production, employment and income) differs (Martin 2012) between regions.

Finally, to reach the purpose of this paper, the concept of resilience has been determined and explained with related terms, which should be used in the Slovenian language by examining economic crisis and recovery afterwards in different spatial levels. 